\title{
INCENTIVIZED TECHBIN: A STEP TOWARDS SUSTAINABLE ENVIRONMENT
}

\author{
Dhruv Vohra \\ Student, Bachelors of Technology \\ Computer Science Engineering \\ Panipat Institute of Engineering and \\ Technology, India
}

\author{
Gunjan \\ Student, Bachelors of Technology \\ Computer Science Engineering \\ Panipat Institute of Engineering and \\ Technology, India
}

\author{
Dr Anju Gandhi \\ Professor, Department of Computer \\ Science and Engineering \\ Panipat Institute of Engineering and \\ Technology, India
}

\begin{abstract}
A point-based Incentivized Tech Bin is an Internet of Things (IoT) supported smart dustbin which functions with smart sensors and provides an interactive user interface that makes bin an intelligent system for waste management. Incentivized bin is supported by a game portal for motivating people to throw garbage especially targeting younger generations to promote better hygiene regimes by throwing garbage into bins and make our environment clean and green. Tech Bin displays a gift token for the bin users based on the frequency of user using the bin. The user is rewarded with a token key each time garbage of more than $1 \mathrm{~kg}$ is dumped into the bin. As World's population is growing every day, hence the need to cultivate and preserve the environment also becomes our priority. Flooded trash bins create unsanitary conditions across public places. The lack of supervision of garbage bins can disturb the environmental balance and, cause deterioration of health and hygiene among people. However, the supervision also acts to be vulnerable to human error and negligence, with the age-old practice of hiring people to routinely search and empty the garbage bins. Besides, routine checks based on time crevices may be ineffective because a garbage bin may be filled early and may require immediate attention. For handling such situations, Tech Bins perform an effective role. It can help in monitoring realtime updates of the capacity of bins and inform municipalities or required authorities. This system is an IoT application that incorporates various features like automatic lid opening, LED display, solar panel, and smart module compactor that increases the efficiency of Bin from the user's perspective. Along with this, the system is compiled up with the open-source tool Arduino that is also convenient to install and manage and becomes the heart of Tech Bin.
\end{abstract}

Keywords - Techbin; Smartbin; Environment; Internet of things; Hygiene; Garbage; Smart cities; Waste.

\section{INTRODUCTION}

A healthy environment is necessary if we want to stay healthy. However, in today's fast-growing world, individuals barely have time to stop and configure things manually. Waste is negligently thrown into every nook and corner that makes it difficult for civil servants, who have to separate it manually, often with bare hands, and also pose as a hazard to health. Large batches of waste disposed off are dangerous to the public because of landfills. To achieve full efficiency, automation is by far most embraced. Scheduled monitoring for the cleanliness of the Trash Bins depending on the time slots is not mandatory because a trash bin may get filled early, or there may not be a need for that. Likewise, to consume less fuel and to make the whole task more efficient and userfriendly, Auto notification to the municipalities would be sent on their systems with the unique Bin ID and location where the bin is installed when $75 \%$ of bin quantity is filled. The finalized routes are then prepared from real-time updates of bins. For the implementation of a smart city, we need some changes in the infrastructure of a current system. Introducing Tech Bins will be a significant step in revolutionizing the world. In recent times, there is a massive growth in population not only in India but on the global level also, which ultimately leads to massive growth in waste disposal. Our work faces the greatest threat today in the form of the Novel Coronavirus, which brings the whole process of garbage disposal even more important than ever before. Taking TechBins into consideration, they are made to overcome all of these anomalies in the current system. Tech bins will be set up throughout the entire city, maintaining the proper distance and preferring the bustling places with more. They have incubated with a tiny controlling device mainly a system with various transducer and sensors, Arduino, GPS module, and GSM electronic device. The information when received, analyzed, and processed inside the cloud service then shows the amount of weight entered into the bin on respective smartphones. They can significantly overcome everyday waste management in cities. 


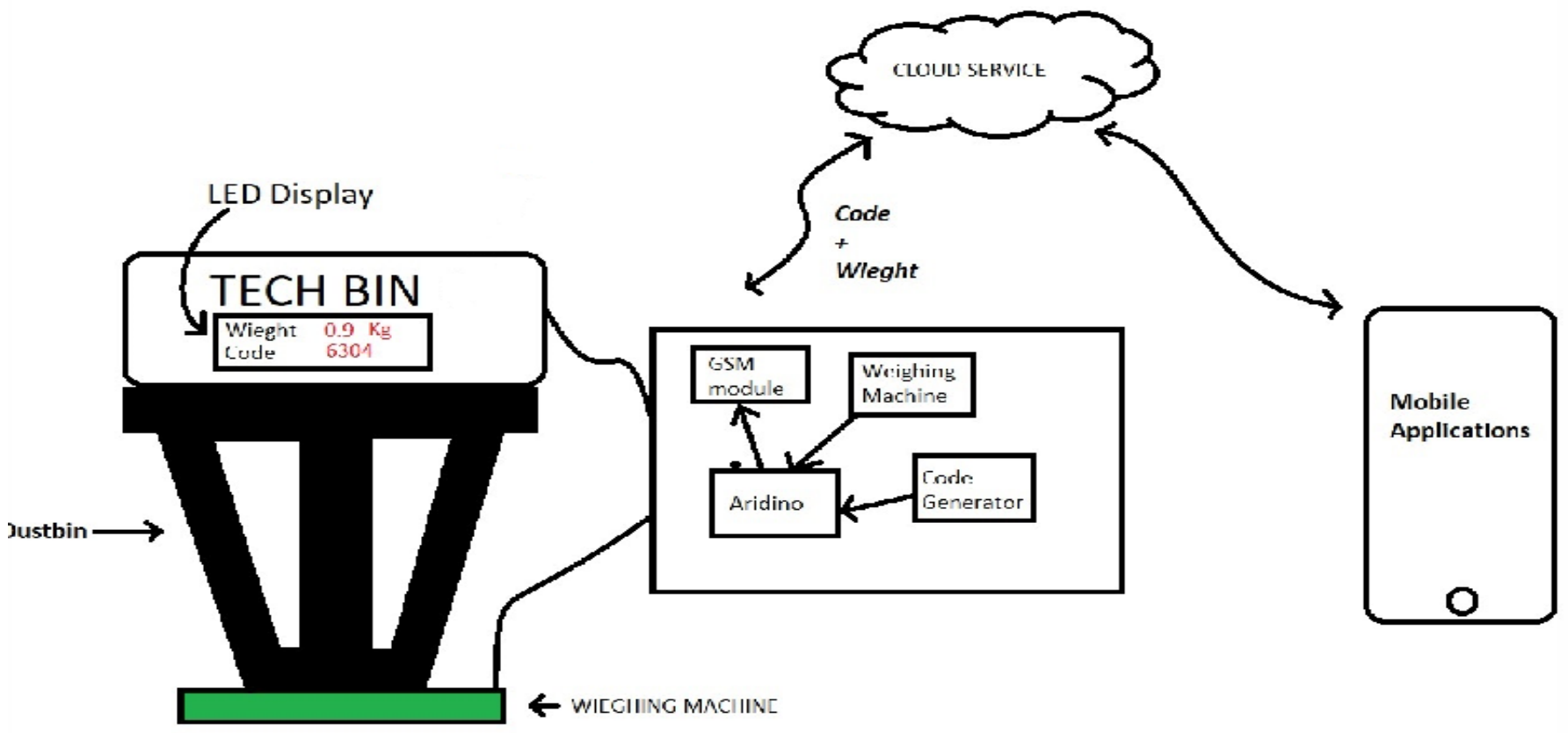

Fig-1 Architechture of Techbin

Also, our honorary, Prime Minister of India, Sri Narendra Modiji, has introduced the idea of implementing a hundred smart cities in India. "Swachh Bharath Abhiyan" is an initiative to state that India will be a clean city and this is by far the most needed tool to make that happen.

\section{LITERATURE REVIEW}

Joshi J et al. (2016) [1] proposed a cloud-based smart bin waste monitoring system where they are using the bundle of IoT devices but according to latest researches, we have more powerful sensors nowadays in place of them they are using whereas they are concentrated only on the part of monitoring the level whereas we are working to increase the efficiency of the bin by introducing the concept of compactor which crushes the garbage and reduces its size which ultimately will result in an increase of bin size up to 8 times. Sathish A et al. (2017) [2] and Poddar $\mathrm{H}$ et al. (2017) [8] proposed the model of intellectual trash management using IoT devices, they have given the real-time solution for monitoring bins using google API and creating a database for their users but their model is a bit more relying on the algorithmic part which may be executable on small samples but not on a population where they are trying to implement this. Considering the amount of waste generation, controlling that is an issue and for dealing with such large people you need an interactive interface that is lacking there. Srinivas M et al. (2019) [3] and Tiwari C et al. (2017) [9] both proposed models which are decent for a modern smart bin where they are maintaining analytics for predicting patterns of bins but the only aspect left is the interface, there should be an application to maintain data and for user satisfaction, whereas we have multiple additions to that in form of a game portal included for the motivation of younger generation into maintaining cleanliness. Xenya $\mathrm{M}$ et al. (2020) [4] they have proposed a solid model including the latest techniques for the city of Ghana, their interactive application design, as well as the build of bins, are appreciable only aspect they could have looked upon is the use of solar energy. Jana B et al. (2019) [5] proposed a moving smart bin system which could be one of the revolutionizing models, considering the design and technologies used. The concept of rollers, automatic lid opening, and sensors in the bin are quite impressive, but the power needed to operate it hasn't been justified in the model. Mithinti S et al. (2019) [6] put forward the smart bin technology measuring the weight of garbage is thrown which they have tested upon, we have also considered this, the overall system is quite good but lacking in the mobile application part where the justification of technology used is lacking. Jayson M et al. (2018) [7] and Ziouzios D et al. (2019) [10] both have proposed models for waste segregation and collection respectively, agenda for both models vary from ours as they are working for a cause of separating it. Their model consist of real-time monitoring of bin size filled and has applied a messaging service for indicating municipalities. Talking about additional features in our system as using solar power is one of the major highlights and safety sensors plus weighing sensors adds to its glory. Murugaanandam S et al. (2018) [11] proposed IoT based smart bin consisting of a model build with extensive use of sensors doing a great job overall, tried using traditional languages such as $\mathrm{C}$ language and HTML for programming and web-based applications comparing it with the model we have preferred the latest technologies python as our programming language and Django as our web framework both in current trends. Wijaya A et al. (2017) [12] proposed a smart waste management system 


\section{International Journal of Engineering Applied Sciences and Technology, 2020 \\ Vol. 5, Issue 2, ISSN No. 2455-2143, Pages 141-148 \\ Published Online June 2020 in IJEAST (http://www.ijeast.com)}

consisting of GSM modules and Bluetooth for Data Transmission, other sensing devices for various aspects such as an ultrasonic sensor for garbage detection. Web-based monitoring was enabled by them for authorities and an application is developed for users. Mahmood I, Zubairi J. et al. (2019) [13] Proposed an IoT based system application to optimize waste transportation processes within a metropolitan area. The whole process was simulated and then the prototype system was physically implemented using a case study of a specific metro region. The proposed system brings several benefits to cities including reduced street congestion, demandbased deployment of waste vehicles, and significant time and fuel consumption savings. We assume that the key insights outlined in this essay will enable academics, smart cities, and industry to develop, replicate, and apply the model to better their lives. Ahmad S et al. (2020) [14] stated the model where they are using the real dataset based on disposal waste in residential areas. Further used an optimization and prediction algorithm produces an efficient route recommendation system. But it is not automated; the manual system could be difficult to manage.

Technology Standouts- Crusher, Solar Cell, Weighing Sensor, use of latest technology sensors are preferred and the game portal is considered for the overall development of Tech Bin as a revolutionary model for the smart system and smart city.

\section{PROPOSED DESIGN OF TECHBIN}

Tech Bin is an efficiently designed system to overcome the current Disposal system customized for public and private use. Starting from its double-layered stainless steel structure build given to overcome the environmental situation and provide solidity to the system.It has been mounted with a solar panel on top which receives sunlight, as shown in Fig 2, and converts it into electrical energy and we have a battery to store its energy to increase its efficiency even at night. Once fully charged, its battery life lasts up to 4 weeks; covering the security aspect of solar panel we have covered it with a polycarbonate sheet which due to its unbreakable nature is perfect for our system.

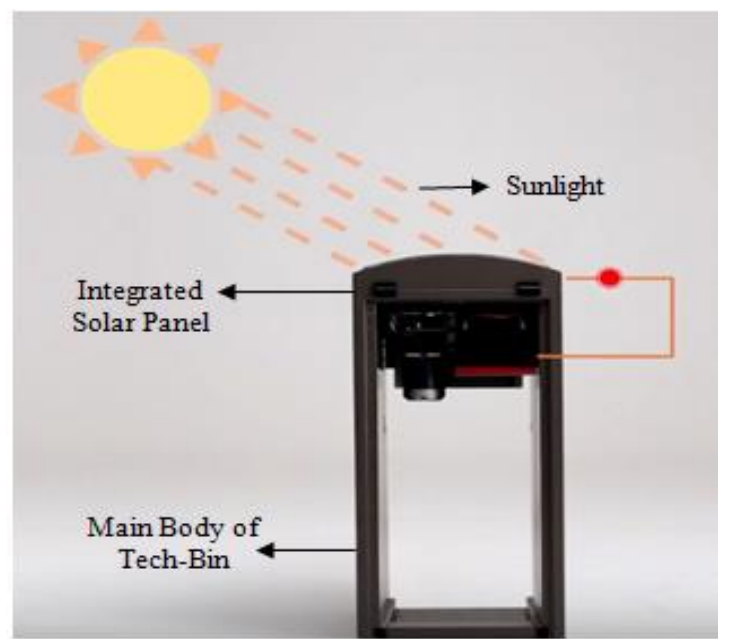

Fig-2 Sunlight Falling On Solar Panel

Its main feature is to maintain cleanliness, it has automatic lid opening feature which is supported by an ultrasonic sensor and safety sensor, DC motor is providing the power to operate for the continuous opening and closing of lid. Behind it, why is it so efficient, so considering that fact we have installed the smart compaction module, as shown in Fig 3, Compactor increases the bin capacity by 8 times than the normal trash Bin. This works on Ultrasonic fill level sensor as it alerts our bin is $75 \%$ filled, ther sensor gives the permission to the compactor to start and press the garbage against the base. The shape of the compaction module is $\mathrm{X}$-Frame and can exert up to $700 \mathrm{~kg}$ force.

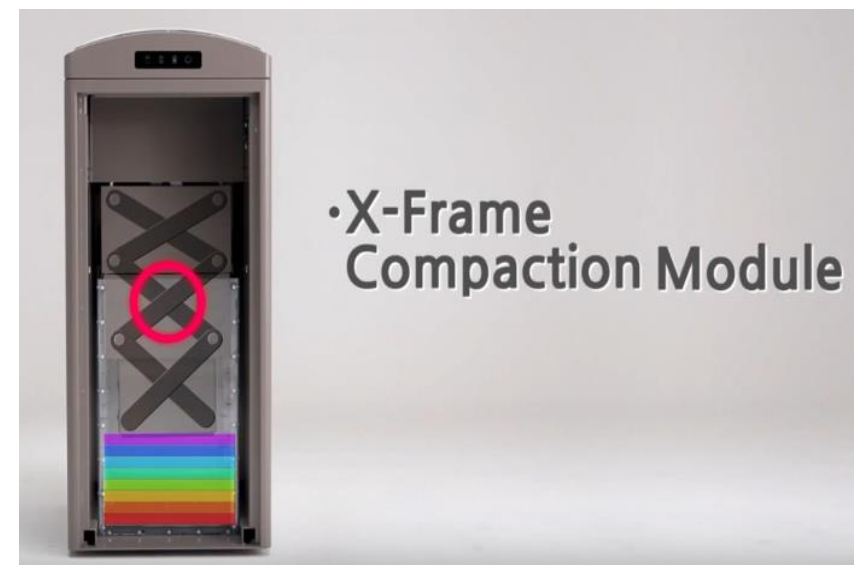

Fig-3 Implementation Of Compactor

Talking about the garbage thrown into the bin is weighted and displayed it onto the screen as there is a weighing sensor and load cells are placed at the bottom structure for the purpose of our game portal. As the user enters some amount of garbage, the weighing sensor measures it, and forward it through the cloud and it is displayed on the screen to the user. If it is more than $1 \mathrm{~kg}$ a code is displayed for the game portal if not, the amount is stored in his account and when he reaches the $1 \mathrm{~kg}$ mark, he will be rewarded with the code. The code generated on the screen is the key to the user playing game in our game portal. User has to enter a key to reach further 


\section{International Journal of Engineering Applied Sciences and Technology, 2020 \\ Vol. 5, Issue 2, ISSN No. 2455-2143, Pages 141-148 \\ Published Online June 2020 in IJEAST (http://www.ijeast.com)}

levels, after every 10 level our portal asks for a key so it motivates our users to throw garbage into Tech Bin and ultimately helps environment get cleaner. Game portal is a portal based on python games and it also maintains the user database for Tech Bin. Additionally, a fire alert sensor for emergencies is placed which gives the alert to the municipalities about the fire. Until they arrive our compactor module tries to deal with fire as pressing it against the steel base can stop the fire. On our led screen display a fire symbol is alerted for human safety.

Cloud is playing an important role in this system as the amount of garbage in a bin is measured and transferred through the cloud so ultimately it helps in generating smart routes throughout the city as all the bins are monitored on a real-time basis as shown in Fig 4, we can have a real-time check on what percentage of the bin is filled, which eventually results in $90 \%$ reduction in waste collection and 10 times less transportation to collect the garbage which leads to less $\mathrm{CO}_{2}$ emissions in our environment so, therefore, it will be beneficial and sound system for ecosystem. By implementing Tech Bin over the city we can have a perfect waste collection system which also enables us to recycle the waste.

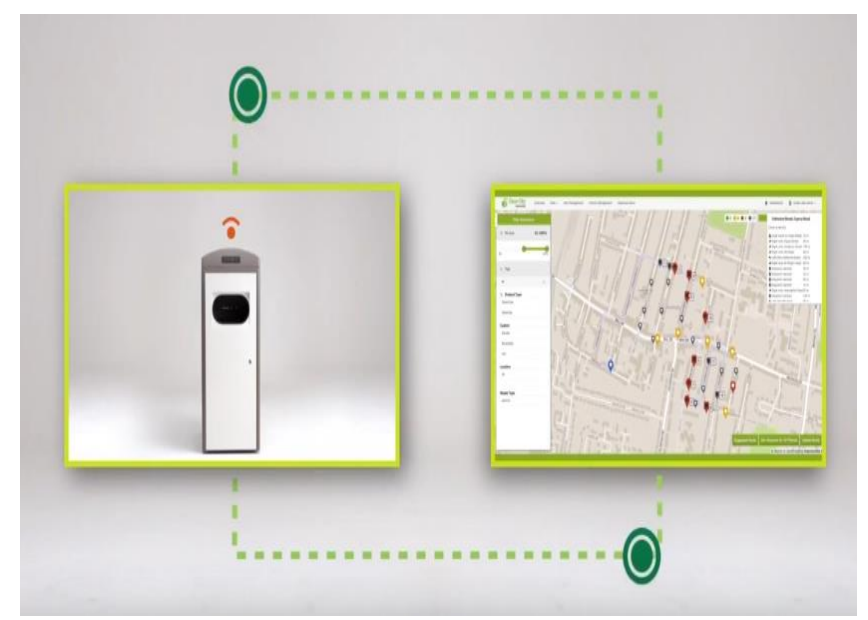

Fig-4 Real Time Monitoring Of Bins

When we deploy each Tech Bin we allot a permanent geostationary location on that ID of device, which develops the network of Bins through the means of a web services, then upload the data on the cloud. After the data is uploaded on cloud, then we apply machine learning algorithms, which affects the sensor data and garbage level prediction is made. To evaluate the current status we carried out the predictive analysis of data for Tech Bins and sent to the client progressive web application. Depending upon predicted data, we manage pickups displayed on the client app. Then schedule for pickup is determined based on a certain set of rules stated as follows:

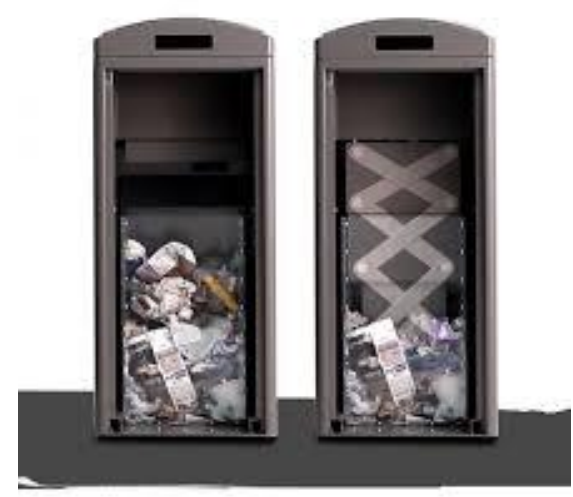

Fig-5 Collection of waste in Bins

a) Safe: Safe state in which the bin is quite empty, garbage needs not to be removed from the bin.

b) Moderate: The Garbage bin is about to get filled to a desired point where is should be looked upon.

c) Critical: Critical state is the point where we need the immediate attention as our bin is about to fill.

d) At least we need 5 bins for a rounding up a schedule.

The respective distribution is defined as $0-50 \%$ for the Safe state, $51-75 \%$ for the Moderate state and for critical stage it is $75 \%$ and so on.

Considering the shortest path, pickups are made according to the schedule, automatically generated by our application.

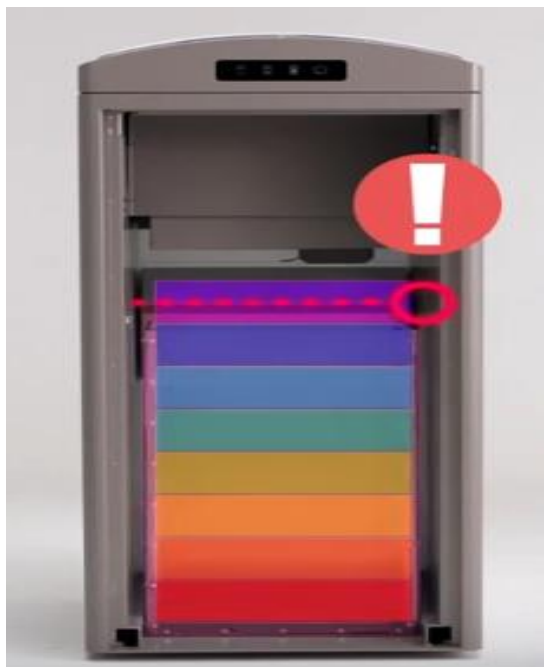

Fig-6 Fill Level Sensor Measures Amount Of Garbage

We can use Tech Bin to generate revenue as it is costing much to our pockets by advertising the commercials as shown in Fig-7 on its back and sidewalls. This generates a huge amount of money which can ultimately increase its implementation chances. 
International Journal of Engineering Applied Sciences and Technology, 2020

Vol. 5, Issue 2, ISSN No. 2455-2143, Pages 141-148

Published Online June 2020 in IJEAST (http://www.ijeast.com)

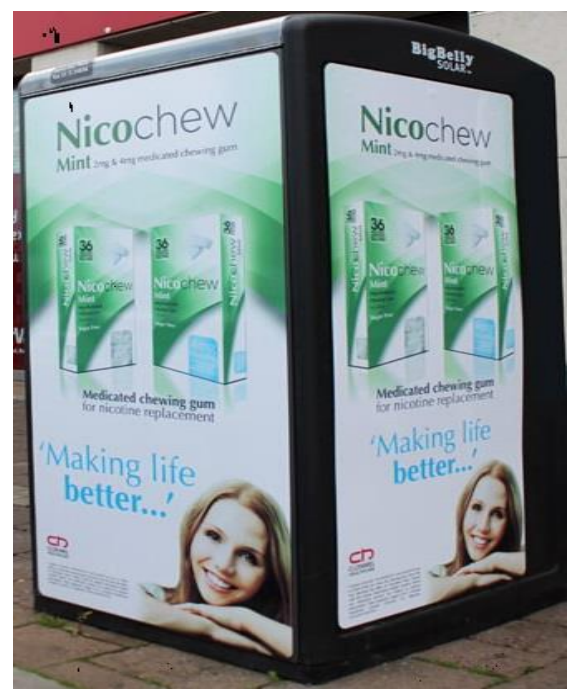

Fig-7 Advertising Commercials

\section{A. Flowcharts}

Weighing procedure explained through the flowchart as shown in Fig-8 as weighing machine is set to zero, then we input the garbage, load cells measure weight and if more than $1 \mathrm{~kg}$ is encountered, it generates code else proceed and reset the weight to zero.

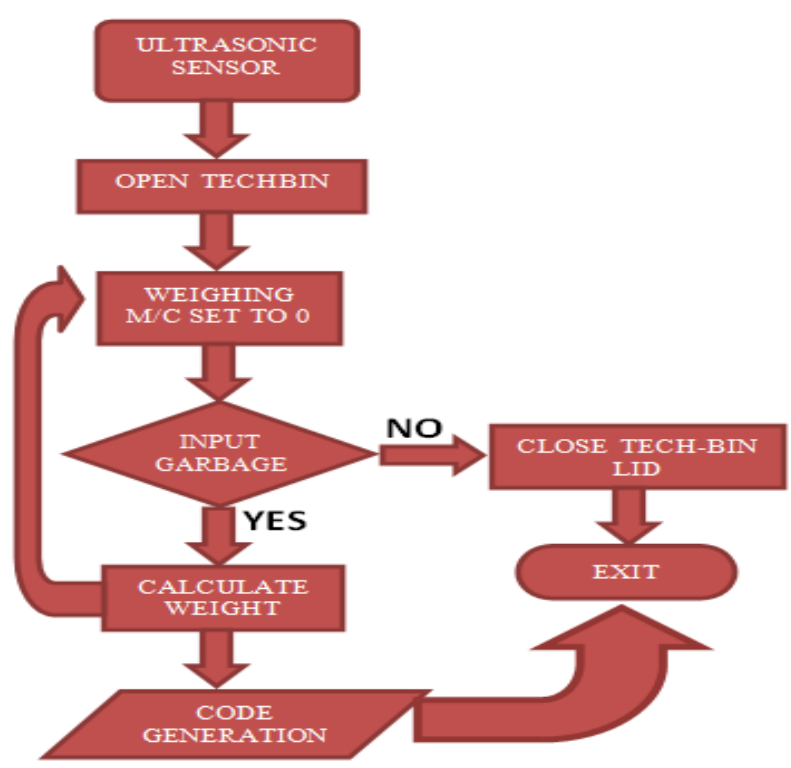

Fig-8 Flowchart Of Weighing Mechanism

Flowchart as shown in Fig-9 explains interface of application, which contains game portal build on python. The user enters Id \& password then proceed to game, if user has a unique code for advance levels it will validate

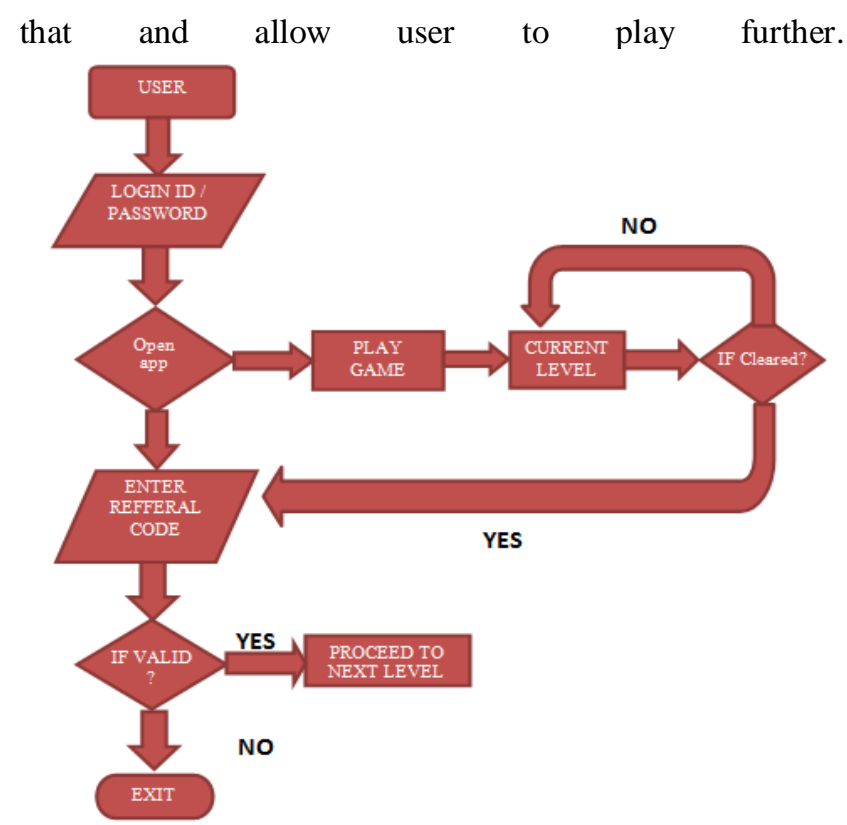

Fig-9 Flowchart Of App Interface

IV. TECHNOLOGIES USED

Tech Bin is unlike any other trash bin in the market, it is procured with the integration of various tools and technology.

\section{A. Hardware}

In Tech Bin, there are several hardware components used for several other aspects such as:

\section{1) IoT Devices:}

An IoT system is a piece of hardware containing a sensor that transmits data over the Internet from one location to another. Types of IoT devices include wireless sensors, computer devices, applications, actuators. They can be incorporated into mobile devices, construction equipment, and sensors for the climate, medical devices, and more. Integrated IoT devices that transmit user and other data may potentially provide insights leading to cost savings, productivity improvements, and new market opportunities for businesses. We have incorporated such devices in this system such as:

\section{a) Arduino}

Arduino is an open-source platform that makes use of software to program hardware. Arduino boards, as shown in Fig-10 consist of a micro-controller and other electronic components that can be programmed to perform various tasks using the Arduino programming language. 


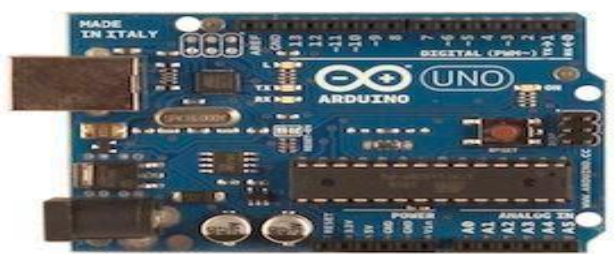

Fig-10 Arduino Chipset

a) Ultrasonic sensor

The Ultrasonic sensor, as shown in Fig-11 implements on same principles like a radar system. An ultrasonic transducer converts electrical waves and vice versa into acoustic waves.

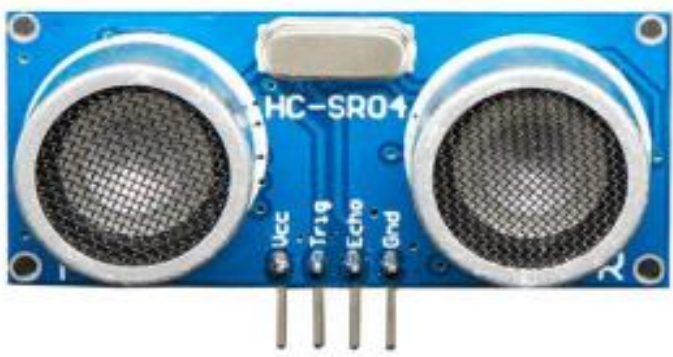

Fig-11 Ultrasonic Sensor

\section{b) Photoelectric safety sensor}

The importance of this kind of sensor is that the light directs to the receiver and works with long detection ranges also high excess rise therefore can be performed. These sensors can be dependable for detecting nearly all object.

\section{c) Fire Detection sensor}

A flame detector is a sensor designed to detect and respond to a fire, allowing flame detection. A flame detector shown in fig-12 responds quicker and with more accuracy than any smoke or heat detector because of the principles it uses to sense the flames.

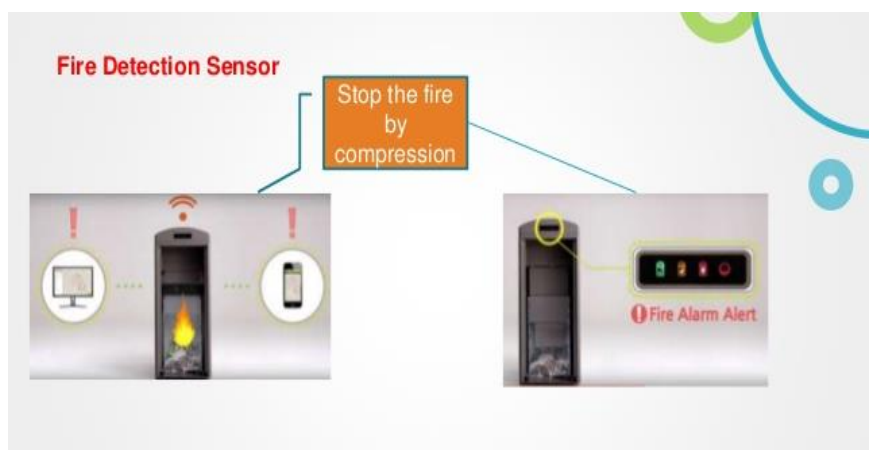

Fig-12 Fire Detection Sensor

a) Weighing sensor and Load Cell
A load cell sensor, as shown in Fig-13 is used which evaluates weight, and performs like an electric signal for this force. Most load cells use strain gauge to sense magnitude and measurement yet there are also available hydraulic and pneumatic load cells. Generally, we have 3 types of load cells but we used the Strain Gauge load cell in this system.

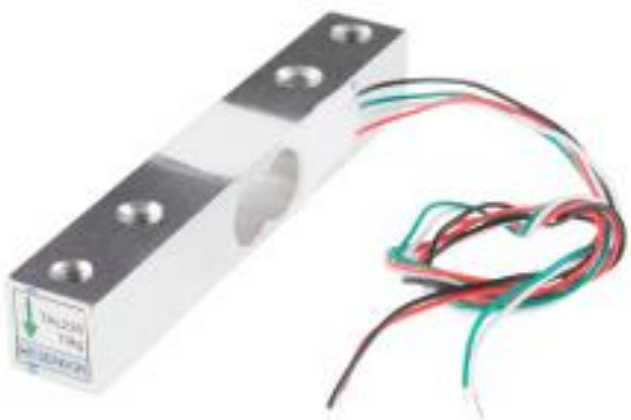

Fig-13 Load Cell

b) Solar Panel

Silicon crystals are stacked on top of each other, laminated into n-type and p-type layers. It is used to store solar energy and works on the principle of photovoltaic effect, i.e. they convert sunlight into direct current also known as DC.

c) DC motor \& battery:

A DC (Direct Current) motor is one class of rotary electric motors that convert any electrical direct current to mechanical energy. Generally forms are dependent on magnetic-field forces. Almost all types of such motors have internal mechanism, either electromechanical or electric, to manipulate the current direction in some part of the motor periodically. Battery is used to store the energy coming from solar cell sources.

\section{d) Wi-Fi Module}

This Module is an independent SOC which has integrated TCP/IP protocol stack that permits to your WiFi network by any microcontroller. It can either host an application or offload all Wi-Fi networking functions from a separate application processor as shown in Fig-14. 


\section{ஓWIFI}

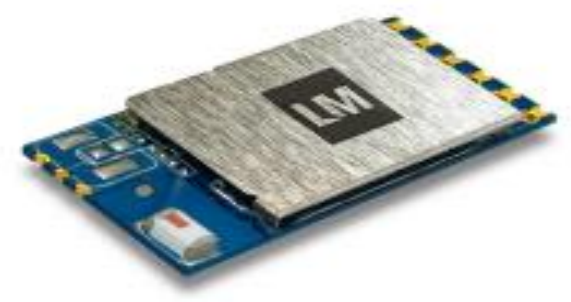

Fig-14 Wireless Module

\section{B. Software}

Tech Bin, uses several software components for making it efficient and user friendly. Those are:

\section{1) Game portal}

Games are developed in a python programming language and integrated into a UI design as shown in Fig-15 with progressive web app structure using react-native.
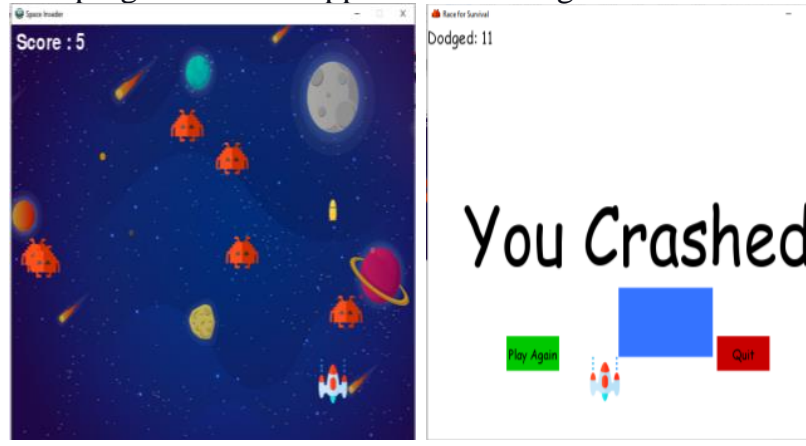

Fig-15 (a) and (b) Screenshots Of Python Game

\section{2) Cloud Services}

Web server is not only your host but your server too. Once the web page you have requested is found, it will also serve you on the web page. So basically the software that receives your request to access a web page is a web server. On your HTTP request, it performs a few security tests and directs you to the home page. The page can ask the server to run a few extra modules while creating the document to support you, depending on the page you have requested. It then provides you with the paper that you have applied for. Apache is the most widely used software on web servers.

Developed and maintained by Apache Software Foundation, Apache is free open-source software. It is running on 63 percent of the world's web servers. It is quick, secure, and reliable. By using extensions and modules it can be highly customized to satisfy the needs of many different environments. Most Word Press hosting providers use Apache as the software for their web server. Word Press can, however, often run on other web server applications.

\section{3) Google API}

For real time monitoring of bins and preparing the shortest schedules for our authorities. We are using Google API of maps which helps in locating bins with garbage on critical stage easily and routes are automated through machine learning algorithms.

\section{4) PyCharm}

PyCharm is an interactive software environment (IDE), primarily for the Python language, used in computer programming. Created by the Czech company JetBrains, it offers application inspection, a graphical debugger, an automated model tester, integration with version control systems (VCSes), and facilitates web creation with Django as well as data science with Anaconda.

\section{ADVANTAGES}

Tech Bin has a lot of advantages, adding intelligence to our dustbin make it a powerful asset for us in many ways:

1) We can stop the overflowing of bins in our localities.

2) Short routes to collect garbage is now available.

3) Less manpower and resources are required.

4) Increases efficiency of bins.

5) Few trucks to collect garbage lead to the saving of fossil fuels.

6) Price Reduction and resource optimization.

7) Less $\mathrm{CO}_{2}$ emissions lead to improved atmosphere quality.

8) No foul smell in our localities.

9) Clean City Green City.

10) Intelligence-Driven Garbage management system in the city.

\section{CONCLUSION}

Nowadays most of the people want to live life in a city environment with having more number of opportunities for growth and success. Now generally in cities the concept of Smart Cities has been introduced and getting very good responses. The conditions like sanitization and cleanliness in today's world are as important as drinking water. Coronavirus has impacted us so badly that now we have to fight and overcome this with a collective effort towards our clean and green environment.

In this study, the researchers have achieved their objective of providing an IoT based system. Tech Bin is a smart waste management system that can be applied in real-time scenarios. This system can monitor the situation or status of each Tech Bin with real-time monitoring so that only if the trash bin is full, will inform the concerned authority to send the garbage assortment vehicle on the shortest prepared route. Long-term work scope is to enforce this system with the use of solar energy for the conservation of energy and promote the idea of green cities. 


\section{International Journal of Engineering Applied Sciences and Technology, 2020 \\ Vol. 5, Issue 2, ISSN No. 2455-2143, Pages 141-148 \\ Published Online June 2020 in IJEAST (http://www.ijeast.com)}

Recently there have been many studies going on to reduce the amount of waste generation and the treatment of disposing of the waste that is in the landfill. This study represents a small but successful step towards cleanliness and providing a better community for people to live in. Therefore, if Tech Bins can be implemented all around the world, the bins are going to be user friendly and life expectancy on earth will also increase.

\section{ACKNOWLEDGMENT}

We would like to thank God for good health and strength to accomplish this study and help us found an innovative way to save the earth. Also, we would like to express our gratitude to the staff and members of the Department of Computer Science, PIET for their help and support to carry out this research. Also, this research could not have been possible without Dr. Anju Gandhi, we would like to thank her for the experience she shared with us that helped a lot in reaching out to conclusions for this project.

\section{REFERENCES}

[1] Joshi J, Reddy J, Reddy P, Agarwal A, Agarwal R, Bagga A et al.(2016). Cloud computing based smart garbage monitoring system, Third International Conference on Electronic Design (ICED) $2016 . \quad$ (DOI: 10.1109/ICED.2016.7804609)

[2] Sathish A, Prakash M, Jainulabudeen S, Sathishkumar R. (2017) Intellectual trash management using Internet of Things, 2017 International Conference on Computation of Power, Energy Information and Commuincation (ICCPEIC) 2017.

(DOI: 10.1109/ICCPEIC.2017.8290338)

[3] Srinivas M, Benedict S, Sunny B. (2019). IoT Cloud based Smart Bin for Connected Smart Cities - A Product Design Approach.Tenth International Conference on Computing, Communication and Networking Technologies (ICCCNT) 2019. (DOI: 10.1109/ICCCNT45670.2019.8944558)

[4] Xenya M, D'souza E, Woelorm K, Nii Adjei-Laryea R, Baah-Nyarkoh E. (2020). A Proposed IoT Based Smart Waste Bin Management System with An Optimized Route: A Case Study of Ghana.Conference on Information Communications Technology and Society (ICTAS) 2020.2 (DOI: 10.1109/ICTAS47918.2020.234005)

[5] Jana B, Roy P, Sengupta S, Porey S, Sen R.(2019). GSM controlled location specific garbage collecting Smart-bin. Ninth Annual Information Technology, Electromechanical Engineering and Microelectronics Conference (IEMECON) 2019. (DOI: 10.1109/IEMECONX.2019.8877007)

[6] Mithinti S, Kumar A, Bokadia S, Agarwal S, Malhotra I, Arivazhagan N.(2019). IoT Based Smart Bin for Smart City Application. International Conference on Intelligent
Computing and Control Systems (ICCS) 2019. (DOI: 10.1109/ICCS45141.2019.9065869)

[7] Jayson M, Hiremath S, H.R. L.(2018). SmartBinAutomatic waste segregation and collection. Second International Conference on Advances in Electronics, Computers and Communications (ICAECC) 2018. (DOI: 10.1109/ICAECC.2018.8479531)

[8] Poddar H, Paul R, Mukherjee S, Bhattacharyya B.(2017). Design of smart bin for smarter cities. Innovations in Power and Advanced Computing Technologies (i-PACT) 2017. (DOI: 10.1109/IPACT.2017.8245162)

[9] Tiwari C, Nagarathna K.(2017) Waste management using solar smart bin. International Conference on Energy, Communication, Data Analytics and Soft Computing (ICECDS) 2017. (DOI: 10.1109/ICECDS.2017.8389615)

[10] Ziouzios D, Dasygenis M.(2019). A Smart Recycling Bin for Waste Classification. Panhellenic Conference on Electronics \& Telecommunications (PACET) 2019. (DOI: $10.1109 /$ PACET48583.2019.8956270)

[11] Murugaanandam S, Ganapathy V, Balaji R.(2018). Efficient IOT Based Smart Bin for Clean Environment. International Conference on Communication and Signal Processing (ICCSP) 2018. (DOI: 10.1109/ICCSP.2018.8524230)

[12] Wijaya A, Zainuddin Z, Niswar M.(2017). Design a smart waste bin for smart waste management. Fifth International Conference on Instrumentation, Control, and Automation (ICA) 2017. (DOI: 10.1109/ICA.2017.8068414)

[13] Mahmood I, Zubairi J.(2019). Efficient Waste Transportation and Recycling: Enabling technologies for smart cities using the Internet of Things. IEEE Electrification Magazine 2019. (DOI: 10.1109/MELE.2019.2925761)

[14] Ahmad S, Imran, Jamil F, Iqbal N, Kim D.(2020). Optimal Route Recommendation for Waste Carrier Vehicles for Efficient Waste Collection: A Step Forward Towards Sustainable Cities. IEEE Access 2020. (DOI: 10.1109/ACCESS.2020.2988173) 